\title{
Kinetics of silicate sorption on magnetite and maghemite: An in situ ATR-FTIR study
}

\author{
Xiaofang Yang a,b,*, Payman Roonasi ${ }^{\mathrm{a}}$, Rickard Jolsterå ${ }^{\mathrm{a}}$, Allan Holmgren ${ }^{\mathrm{a}}$ \\ a Division of Chemistry, Department of Chemical Engineering and Geosciences, Luleå University of Technology, SE-97187 Luleå, Sweden \\ ${ }^{\mathrm{b}}$ Research Center for Eco-Environmental Sciences, Chinese Academy of Sciences, Beijing 100085, China
}

\section{A R T I C L E I N F O}

\section{Article history:}

Received 30 September 2008

Received in revised form 20 January 2009

Accepted 30 January 2009

Available online 8 April 2009

\section{Keywords:}

Silicate sorption

Magnetite

Maghemite

In situ ATR-FTIR

\begin{abstract}
A B S T R A C $T$
Attenuated total reflection Fourier transform infrared (ATR-FTIR) spectroscopy was used to monitor the in situ sorption of sodium metasilicate from aqueous solution onto synthesized magnetite and maghemite particles in the $\mathrm{pH}$ range of 10.8-7.0 using silicate concentrations between $0.1 \mathrm{mM}$ and $5 \mathrm{mM}$. The spectral data showed that both $\mathrm{pH}$ and silicate concentration had great influence on the interfacial reaction between soluble silicate and the iron oxide surfaces, regarding the amount adsorbed per unit mass of iron oxide and the surface species formed. A pH dependent sorption of silicate on iron oxides was observed, implying that a maximum sorption took place in the $\mathrm{pH}$ range of 9.5-7.0. All experiments showed a fast initial increase in the absorption intensity followed by a slower sorption stage which was strongly dependent on the concentration of silicate in solution and the $\mathrm{pH}$ value. The amount of sorption onto magnetite was 3-5 times larger than onto maghemite, but there was no significant difference in the line shape of corresponding absorption bands. At $\mathrm{pH} 8.5$ and low concentration $(\leq 0.1 \mathrm{mM})$, the silicate monomers dominate in solution and on the iron oxide surface also monomeric species were dominating as evident from the infrared band at $950 \mathrm{~cm}^{-1}$. However, at higher concentration $(0.4-5.0 \mathrm{mM})$, the dominating absorption band at about $1000 \mathrm{~cm}^{-1}$ shifted to higher frequency during the sorption indicating that oligomeric surface silicate species were formed on the iron oxide surface. Desorption of silicate from the surface of the iron oxides was easier to accomplish at low silicate concentration, whilst the highest concentration showed a comparatively low relative amount of desorbed silicate, suggesting that polymerized species had a stronger affinity for the iron oxide surface as compared to monomeric species.
\end{abstract}

(c) 2009 Elsevier B.V. All rights reserved.

\section{Introduction}

Interfacial reactions between soluble silicates and iron oxide surfaces are of great importance in the natural environment considering the content of dissolved silicate in natural waters from mineral weathering [1-3] as well as in industrial applications, e.g., flotation of salt-type minerals from metal oxides and other salttype minerals where sodium silicate is usually used as dispersion or depressant agent [4]. Concretely, in the dephosphorizing flotation of magnetite particles, sodium silicate with modulus 3.25 (weight ratio of $\mathrm{SiO}_{2}$ to $\mathrm{NaO}_{2}$ ) is used mainly to disperse the agglomerated particles [5], whereas in the flotation of apatite from hematite sodium silicate may be utilized as a selective depressing agent to reduce the flotation of the gangue mineral (hematite) [6]. It is well known that the concentration, modulus, and $\mathrm{pH}$ of sodium silicate

\footnotetext{
* Corresponding author at: Division of Chemistry, Department of Chemical Engineering and Geosciences, Luleå University of Technology, SE-97187 Luleå, Sweden. Tel.: +46 0 920492284; fax: +46 0920491199.

E-mail address: xiaofang.yang@ltu.se (X. Yang).
}

solutions are the main factors determining selective silicate sorption on mineral surfaces and that the properties of the modifying agent is strongly influenced by the distribution of silicate species in solution viz. monomers, oligomers, higher polymers, and colloidal silica [6-9].

During the past decades, the study of interaction between silicate and iron oxides as well as other minerals was mainly carried out by batch adsorption experiments, modeling methods, and ex situ spectroscopy techniques [1,3,7,10-12]. However, there are very few if any in situ studies on the sorption of silicate species onto magnetite showing the formation of surface complexes with time. Another topic is the often appearing question whether the surface of the magnetite particles, which during experimental handling may be exposed to air, represents magnetite or to some extent are oxidized to maghemite although the structure of the two iron oxides is similar both representing a spinel structure with tetrahedral and octahedral sites [13]. In maghemite, all or most of the octahedral Fe (II) in magnetite are oxidized to trivalent implying a Fe (II)-deficient structure with a slightly smaller unit cell volume as compared with magnetite. From a surface chemical point of view, the important question is whether the sorption behaviour of sodium silicate onto 
the two mentioned iron oxides is the same or if the oxidization state of the iron atoms has a significant influence on the affinity of the surfaces for silicates. Moreover, a molecular level investigation of silicate species sorbed on iron oxide surfaces and especially the time dependence of the sorption is critical in industrial processes with limited conditioning times but also important in geochemical systems.

Accordingly, in the present study attenuated total reflection Fourier transform infrared (ATR-FTIR) spectroscopy was utilized to monitor the sorption of sodium silicate onto a thin layer of synthetic magnetite $\left(\mathrm{Fe}_{3} \mathrm{O}_{4}\right)$ nanoparticles as compared with the sorption onto a corresponding layer of synthetic maghemite $\left(\gamma-\mathrm{Fe}_{2} \mathrm{O}_{3}\right)$. The study encompassed different $\mathrm{pH}$ and silicate concentration. Of special interest here was the possible change of sorbed species at the iron oxide surfaces with time and the possible difference in the amount sorbed under similar experimental conditions. In addition, desorption of the already adsorbed silicate species was studied, possibly revealing the type of surface complexes formed and the affinity of different silicate species for the surfaces.

\section{Experimental}

\subsection{Chemicals and materials}

Sodium metasilicate $\left(\mathrm{Na}_{2} \mathrm{SiO}_{3} \cdot 9 \mathrm{H}_{2} \mathrm{O}\right)$ from Sigma was dissolved in Milli-Q water and prepared as a stock solution ( $0.5 \mathrm{M}, \mathrm{pH}>11.5)$. Magnetite used in this study was synthesized based on a coprecipitation of $\mathrm{Fe}$ (II) and $\mathrm{Fe}$ (III) chlorides method described by Jolivet et al. and Jarlbring et al. [14,15]. Briefly, Fe (II)/Fe (III) chloride salt mixture (1:2 molar ratio) was hydrolyzed using $\mathrm{NH}_{4} \mathrm{OH}$, purified with deoxygenated Milli-Q water, and stored under argon atmosphere. Maghemite was prepared by heating magnetite in an oven at $240{ }^{\circ} \mathrm{C}$ overnight. The BET surface area of magnetite was $97.7 \mathrm{~m}^{2} \mathrm{~g}^{-1}$ and that of maghemite was $87.3 \mathrm{~m}^{2} \mathrm{~g}^{-1}$.

All other reagents were of analytical grade and all solutions were prepared from Milli-Q water as solvent. $\mathrm{NaOH}$ and $\mathrm{HCl}$ solutions were used for $\mathrm{pH}$ adjustments.

\subsection{FTIR measurements}

Spectral data were acquired with a Bruker IFS 66v/S FTIR spectrometer equipped with a deuterated triglycine sulphate (DTGS) detector and a vertical ATR accessory. The vertical ATR accessory consisted of a trapezoidal-shaped $\mathrm{ZnSe}$ internal reflection element $\left(45^{\circ}, 50 \mathrm{~mm} \times 20 \mathrm{~mm} \times 2 \mathrm{~mm}\right.$, totally 25 -reflections) and a singlechamber $(\sim 3.5 \mathrm{~mL})$ flow-through stainless steel cell. Spectra of silicate sorbed on iron oxide were recorded by averaging 100-200 scans at a resolution of $4 \mathrm{~cm}^{-1}$. All spectral data evaluations were performed with the OPUS program from Bruker Optics.

\subsection{Preparation of iron oxide films on the ATR crystal}

A visually evenly distributed magnetite or maghemite film was deposited on one side of the ATR crystal by spreading a certain amount of the iron oxide dispersion on the crystal surface and subsequently evaporate the dispersion medium in a desiccator under vacuum. After rinsing the deposited film gently with Milli-Q water and let it dry in the desiccator again, the mass of deposited film was weighted. Since the dispersion was allowed to stand for a while after stirring to let the larger particles settle down, the concentration of the dispersion dispensed using a pipette varied to a certain extent. Thus the mass of the film was not exactly controlled but only weighted and amounted to generally less than $1 \mathrm{mg}$. Accordingly, the bulk silicate concentration can be assumed to be effectively constant during the experiments.

\subsection{ATR-FTIR spectra of sorbed silicate}

In situ ATR infrared measurements were performed using the flow-cell technique described by Peak and others [16,17]. The small amount of iron oxide used ( $<1 \mathrm{mg}$ ) assures that the depth of penetration is much larger than the thickness of the evenly distributed oxide layer. The $\mathrm{pH}$ of the silicate solution was monitored by a combined $\mathrm{pH}$ electrode and adjusted when needed. The solution $(100 \mathrm{~mL})$ was pumped from a beaker into the flow-cell by a peristaltic pump at a flow-rate of $\sim 4.7 \mathrm{~mL} \mathrm{~min}^{-1}$. Single beam background spectra of the solvent (Milli-Q water) were recorded at each $\mathrm{pH}$. Sodium silicate was added into the vessel at a desired concentration and $\mathrm{pH}$ adjusted with $\mathrm{NaOH} / \mathrm{HCl}$. Spectra of sorbed silicate were recorded as a function of time. Desorption experiments were carried out by flushing flow-cell with Milli-Q water at desired $\mathrm{pH}$. All experiments were performed under ambient temperature $\left(22 \pm 1^{\circ} \mathrm{C}\right)$.

\section{Results and discussion}

\section{1. $p H$ dependent silicate sorption/desorption kinetics onto magnetite}

According to Fig. 1a and b, infrared spectra recorded upon sorption from a $1 \mathrm{mM}$ silicate solution at $\mathrm{pH} 10.8$ is quite different from corresponding spectra at $\mathrm{pH}$ 8.5. At $\mathrm{pH} 10.8$ the strongest absorption had its peak position at $952 \mathrm{~cm}^{-1}$ with a shoulder at $\sim 1020 \mathrm{~cm}^{-1}$. This shoulder is hardly detected at the beginning of the sorption reaction but grows in intensity with the time of reaction. At this $\mathrm{pH}$ value, the dominant species in solution is $\mathrm{SiO}(\mathrm{OH})_{3}{ }^{-}$(Fig. 2, Table 1) [18] and the magnetite surface should be negatively charged since its point of zero charge is $\sim 6.0$ [19]. These spectral changes indicate different inner-sphere surface complexes appear at the magnetite surface during sorption. Comparing the sorption and the desorption it also seems that the absorbance at $\sim 1020 \mathrm{~cm}^{-1}$ upon sorption increases faster relative to the $952 \mathrm{~cm}^{-1}$ band than the absorbance at $\sim 1020 \mathrm{~cm}^{-1}$ decreases relative to the $952 \mathrm{~cm}^{-1}$ band during desorption. These in situ ATR-FTIR results were compared with EXAFS results of Pokrovski et al. [20] on iron(III)-silica coprecipitate, strongly indicating that the $952 \mathrm{~cm}^{-1}$ band should be assigned to the bidentate monomeric surface species, $(=\mathrm{FeO})_{2}-\mathrm{Si}(\mathrm{OH}) \mathrm{OH}$ or $(\equiv \mathrm{FeO})_{2}-\mathrm{Si}(\mathrm{OH}) \mathrm{O}^{-}$, whilst the shoulder at $\sim 1020 \mathrm{~cm}^{-1}$ should be assigned to oligomeric surface silicate species which desorbed slower than monomeric species.

At $\mathrm{pH} 8.5$, it is interesting to notice that the oligomeric species is dominating already at the beginning of the sorption reaction although the peak frequency of the absorption band appears at lower wavenumber $\left(1000 \mathrm{~cm}^{-1}\right)$. This might indicate a difference in the degree of oligomerization with fewer monomer units in the oligomer at the beginning of the sorption reaction. Since these oligomers do not dominate in aqueous solution at this low concentration ( $1 \mathrm{mM}$, Fig. 2 ), it further indicates that the polymerization occurs at the magnetite surface. This latter suggestion is in accordance with results from the literature [2,7], showing that polymerization of silicic acid on an iron oxide surface is promoted at lower $\mathrm{pH}$. At longer sorption times, it is also evident from the experiments at $\mathrm{pH} 8.5$ that an infrared absorption at wavenumbers $>1100 \mathrm{~cm}^{-1}$ evolves. This absorption band is consistent with a three-dimensional polymeric structure such as colloidal silica [21] and would imply that the polymerization of silica occur at the magnetite surface also at this low concentration of silica in solution (1 mM).

The $\mathrm{pH}$ dependence of silicate sorption from $1 \mathrm{mM}$ sodium silicate solution onto magnetite was determined by collecting ATRFTIR spectra of sorbed silicate with time at the $\mathrm{pH}$ values; 10.8, 9.5, 


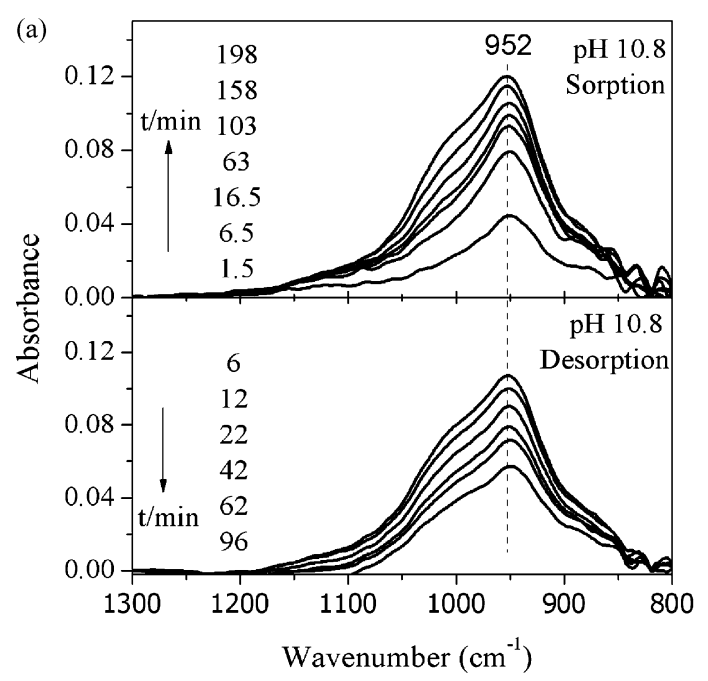

(b)

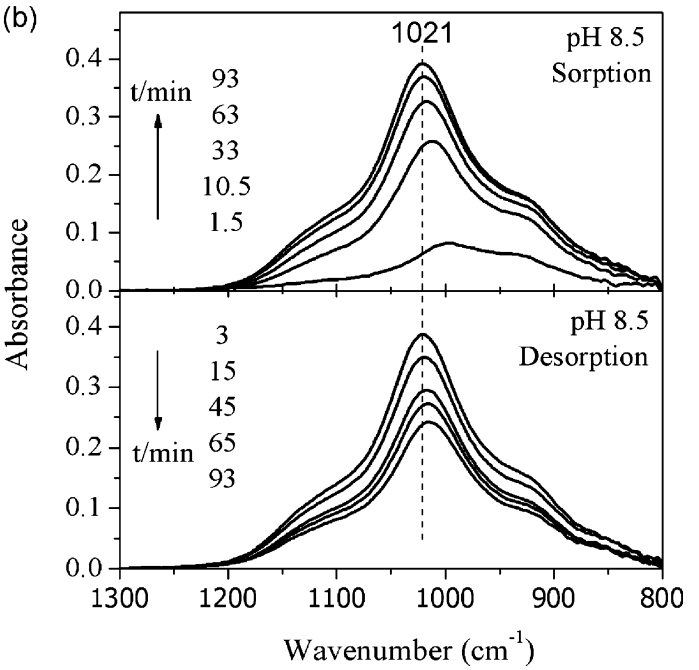

Fig. 1. ATR-FTIR spectra of silicate sorbed onto magnetite from $1 \mathrm{mM}$ sodium metasilicate aqueous solutions. The time dependence of the sorption is shown for (a) $\mathrm{pH} 10.8$ and (b) $\mathrm{pH} 8.5$.

8.5, and 7.0 (Fig. 3). In Fig. 3, the infrared absorbance caused by silicate was integrated between $1300 \mathrm{~cm}^{-1}$ and $800 \mathrm{~cm}^{-1}$ and divided by the mass of magnetite deposited as a thin layer on the ATR crystal and then this ratio was plotted versus the reaction time. It can be clearly seen that from $\mathrm{pH} 10.8$ to $\mathrm{pH} 8.5$, the integrated intensity

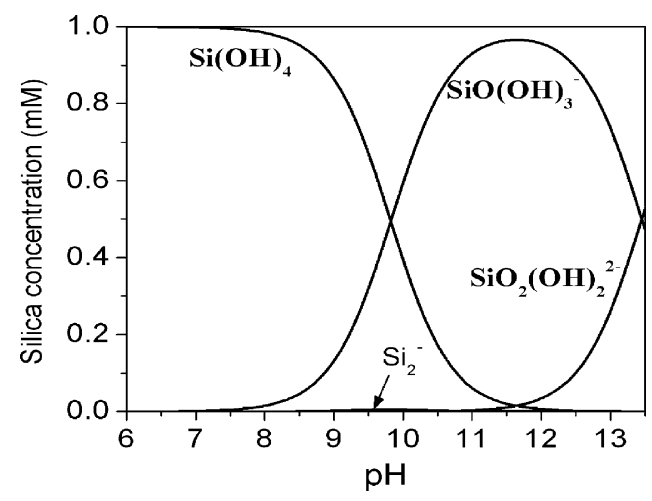

Fig. 2. The diagram shows the distribution of silicic acid/silicate anions in aqueous solution as a function of $\mathrm{pH}$. The total silica concentration was $1 \mathrm{mM}$ and the thermodynamic equilibrium constants are listed in Table 1.

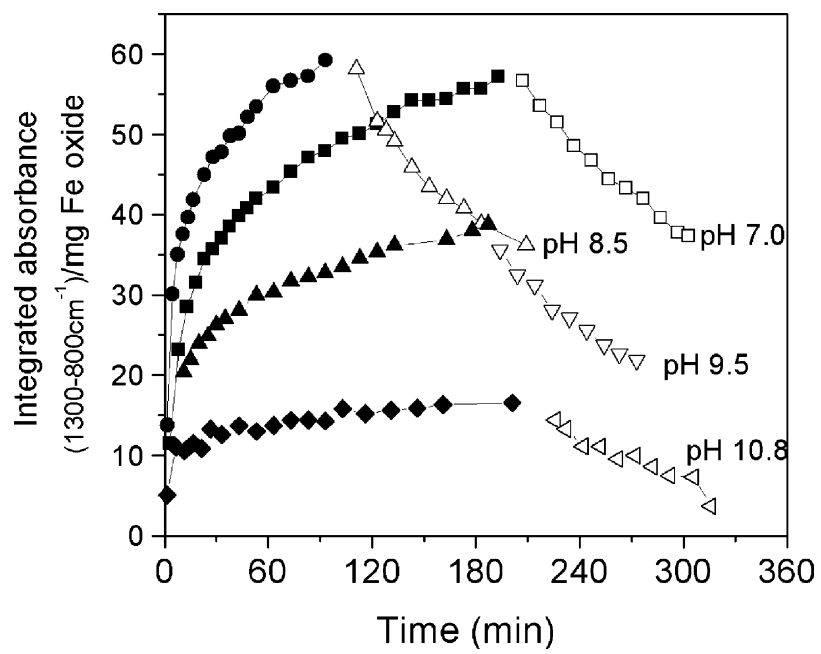

Fig. 3. Sorption of silicate from $1 \mathrm{mM}$ sodium metasilicate aqueous solution at different $\mathrm{pH}$ onto magnetite followed by desorption. Filled circles, integrated absorbance of sorbed silicate per mg magnetite; open circles, integrated absorbance of residual silicate on surface during desorption. Infrared spectra were integrated between $1300 \mathrm{~cm}^{-1}$ and $800 \mathrm{~cm}^{-1}$.

of sorbed silicate increased with decreasing $\mathrm{pH}$. However, when $\mathrm{pH}$ was lowered to 7.0 the integrated intensity decreased implying that there is a maximum in the amount of sorbed silica. This $\mathrm{pH}$ dependent silicate sorption behaviour of magnetite is consistent with previous studies $[1,7,11,12]$ where thermodynamic models have been used to explain the observed maximum. The decreased amount of sorbed silicate between $\mathrm{pH} 8.5$ and $\mathrm{pH} 7.0$ occurred in a $\mathrm{pH}$ interval where the charge of the silicate species in solution is neutral (Fig. 2) and that of the magnetite surface is still negative although decreasingly so with $\mathrm{pH}$. However, the condensation of silicate monomers is promoted at the magnetite surface at lower $\mathrm{pH}[2,7,22]$. The decreased sorption of silicate from $\mathrm{pH} 8.5$ to $\mathrm{pH} 7.0$ could therefore be attributed to the decreased availability of surface sites caused by condensation reactions masking otherwise available $\equiv \mathrm{Fe}-\mathrm{OH}$ sites and/or the decrement of ionic silicate species which are essential to the sorption reaction. The measured absorbance of the infrared spectrum is proportional to the square of the vector product between the electric field vector of the evanescent field $(E)$, which mainly depends on the thickness of the iron oxide layer in the present case, and the transition dipole moment $(M)$, which should relate to the structure of formed surface silicate species. Using an equation proposed by Dobson et al. [23], the absorption may be described as:

$A_{i}=\varepsilon_{i} \Gamma_{i}^{\prime} \frac{d_{e}}{t}$

where $A_{i}$ is the measured absorbance of the $i$-species, $\varepsilon_{i}$ is the molar absorption coefficient of sorbed silicate species, $\Gamma_{i}^{\prime}$ is the apparent surface loading concentration, $t$ is the thickness of the deposited layer on the crystal, $d_{e}$ is the effective path length determined by the refractive indices of the internal reflection element and the medium outside, by the thickness of the layer, angle of incidence, and the wavelength of the infrared radiation.

As a first approximation, it is assumed that the molar absorption coefficients of sorbed silicate species formed at different $\mathrm{pH}$ are not changing with the amount sorbed or are experienced to the same relative change. This assumption is reasonable, at least for $\mathrm{pH}$ 9.5-7.0, considering the similarities in line shapes of the infrared spectra of sorbed silicate within this $\mathrm{pH}$ range (not shown here, but in [22]). Except at extremely high $\mathrm{pH}$ ( $\mathrm{pH} 10.8$ ), showing a different line shape, the spectral line shapes recorded at $\mathrm{pH} 7.0,8.5$, and 9.5 were very similar indicating similar silicate species on the iron 
oxide surface at each $\mathrm{pH}$ value and that the relative amount of these species were also similar. Between different series of spectral data at a certain $\mathrm{pH}$, the mass of the deposited magnetite layer varied from $1.0 \mathrm{mg}$ to $0.3 \mathrm{mg}$. For the experiments at $\mathrm{pH} 7.0$ and $\mathrm{pH} 8.5$, the mass of the magnetite layer was close to $0.3 \mathrm{mg}$, and at $\mathrm{pH} 9.5$ and $\mathrm{pH} 10.8$ the amount of magnetite was close to $1.0 \mathrm{mg}$. However, the integrated intensity of infrared absorption should be proportional to the mass of the magnetite layer. Despite of the uncertainty of the $d_{e} / t$ ratio in Eq. (1) that restricted the application of accurate quantitative comparison between different experimental series, the time dependent trend of silicate sorption onto magnetite, as shown in Fig. 3, should be true in this $\mathrm{pH}$ range. It should be noticed that the line shape and peak frequency position of the absorption bands at $\mathrm{pH} 10.8$ is different from the ones at lower pH (Fig. 1) and therefore a direct comparison of sorbed amounts between high (10.8) and low (9.5-7.0) pH values in Fig. 3 is more uncertain. However, it seems still plausible to suggest that the highest $\mathrm{pH}$ value imply a lower amount of sorbed silica, which is also supported by results from others $[1,7,11,12]$. Desorption experiments carried out directly after sorption at a certain $\mathrm{pH}$ were used to assess the sorption affinity of silicate for the magnetite surface. The residual silicate on the magnetite surface was monitored during the time the flowcell was flushed with Milli-Q water. ATR-FTIR spectra are shown in Fig. 1 and desorption results are plotted in Fig. 3. During the time of desorption used here $(\sim 2 \mathrm{~h})$ it is clear that silicate is more easily desorbed at high $\mathrm{pH}$ than at low $\mathrm{pH}$. This might be caused by the formation of oligomeric surface silicate species at low $\mathrm{pH}$. Formation of such species would imply stronger interaction with the magnetite surface since each species may offer many $\mathrm{Fe}-\mathrm{O}-\mathrm{Si}$ bonds with the surface and therefore it takes longer time to desorb these species. On the other hand high pH would imply an enhanced detachment of sorbed silicate as ions in accordance with the silica dissolution mechanism and an increased electrostatic repulsion between magnetite surface and silicate species which should facilitate the desorption and inhibit the resorption as well. Although the desorption rate seemed to be higher in the beginning of the desorption reaction, an equilibrium plateau value was not reached within $2 \mathrm{~h}$.

\subsection{Effect of silicate concentration on sorption}

In Figs. 4 and 5, the sorption of silicate from aqueous solution onto magnetite (Fig. 4) and maghemite (Fig. 5) is shown at pH 8.5 and different silicate concentration. Clearly, the concentration as well as $\mathrm{pH}$ is important for the type of surface complexes formed. At the lowest concentration ( $0.1 \mathrm{mM}$, Fig. 4$)$, the recorded spectra reminds very much of spectra recorded at $\mathrm{pH} 10.8$ but for a higher silicate concentration (1 mM, Fig. 1a). Accordingly, the $950 \mathrm{~cm}^{-1}$ band is due to bidentate monomeric surface species, whilst the shoulder at the high frequency side of this band demonstrates the formation of oligomeric species. At the highest silicate concentration ( $5 \mathrm{mM}$ ), the dominant band at $\sim 1020 \mathrm{~cm}^{-1}$ for a $1 \mathrm{mM}$ solution is shifted to $\sim 1050 \mathrm{~cm}^{-1}$ upon increased surface loading. This is an interesting spectral shift because a higher silicate concentration is expected to result in more of polymeric species. Accordingly, the shift from $1020 \mathrm{~cm}^{-1}$ to $1050 \mathrm{~cm}^{-1}$ is an indication of increased polymerization at the magnetite surface resulting in oligomeric species with a higher degree of polymerization but may simultaneously reflect a change of the structure of the oligomers since infrared spectra are well-known to be sensitive to changes in molecular structure. Sorption from a $5 \mathrm{mM}$ aqueous silicate solution also imply a much higher intensity at $1100-1150 \mathrm{~cm}^{-1}$, which was assigned to a three-dimensional framework such as amorphous silica. However, the broadness of this band is significantly larger than the half-width of a spectrum of amorphous silica particles (not shown) although the peak frequency is almost the same. This might

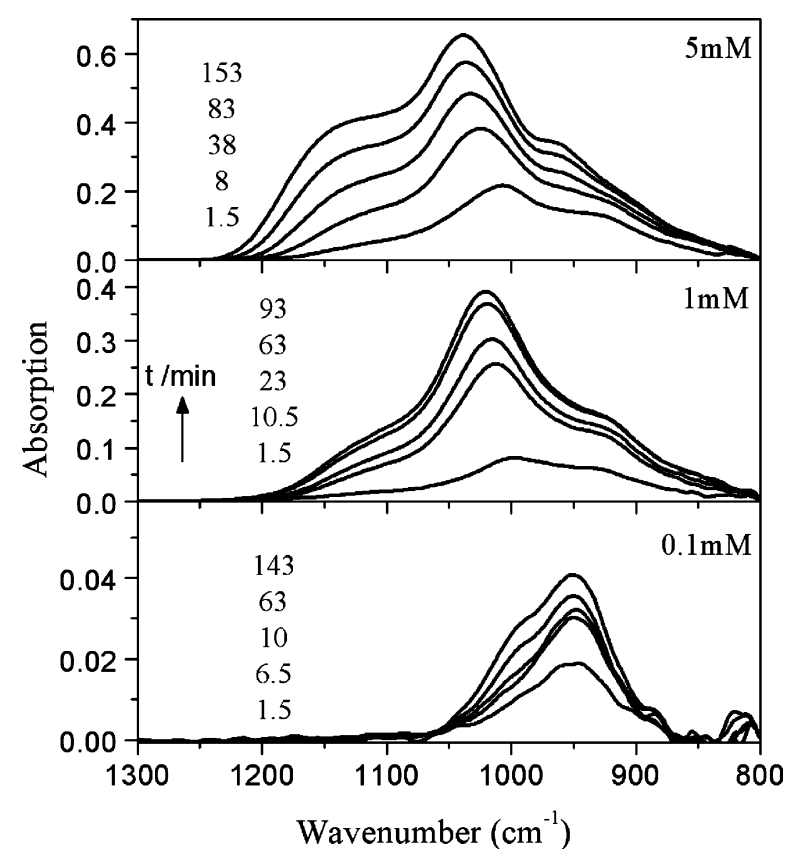

Fig. 4. ATR-FTIR spectra showing the time dependence of silicate sorption on magnetite at $\mathrm{pH} 8.5$ and different silica concentration.

imply that the three-dimensional silica framework structure eventually will form a silica layer which infrared spectrum is similar to the spectrum of amorphous silica particles. It might be speculated that the appearance of such a broad band in this region could be due to the number of $\mathrm{Si}-\mathrm{O}-\mathrm{Si}$ units exposed to different environments such as in cyclic trimers, mono-substituted cyclic tetramers, cyclic tetramers, bridged cyclic tetramers etc. If these units represent slightly different vibrational potentials with low activation energy between them, the result should be a broadening of the absorption band caused by $\mathrm{Si}-\mathrm{O}$ vibrations.

Fig. 5 shows that vibrational spectra of silicate sorbed on a maghemite surface at $\mathrm{pH} 8.5$ are very similar to the correspond-

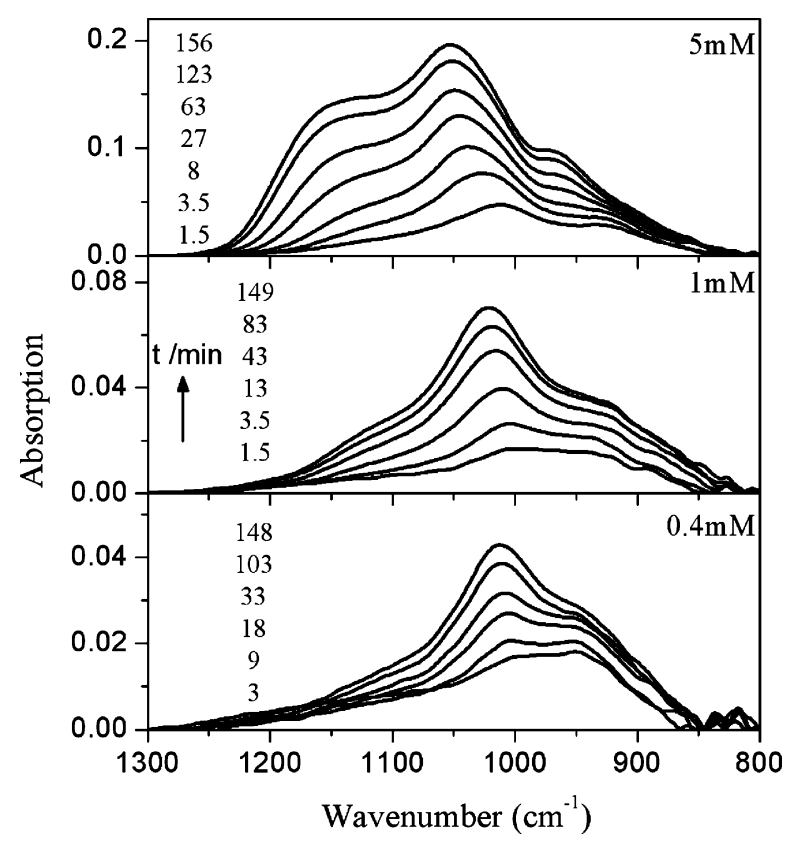

Fig. 5. ATR-FTIR spectra showing the time dependence of silicate sorption on maghemite at pH 8.5 and different silica concentration. 

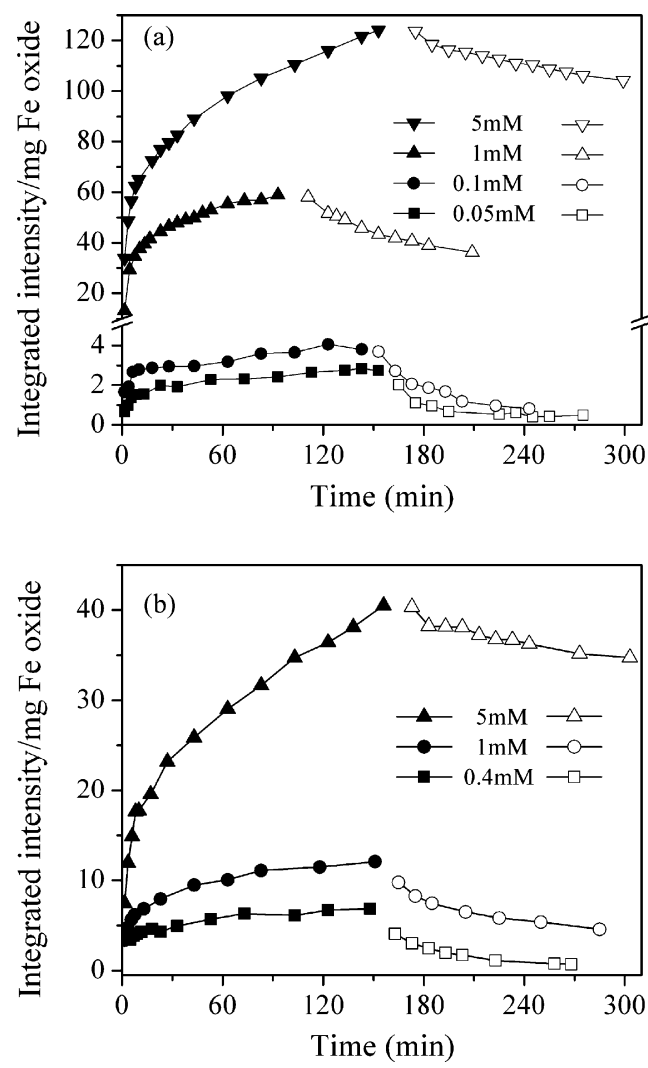

Fig. 6. Sorption and desorption of sodium silicate at $\mathrm{pH} 8.5$ and different silica concentration: (a) magnetite and (b) maghemite. Filled circles; integrated absorbance of sorbed silicate per mg magnetite; open circles, integrated absorbance of residual silicate on surface during desorption. Infrared spectra were integrated between $1300 \mathrm{~cm}^{-1}$ and $800 \mathrm{~cm}^{-1}$.

ing spectra for silicate on magnetite. Spectra recorded for sorption from a $1 \mathrm{mM}$ solution are similar in line shape compared to corresponding spectra obtained for magnetite (Fig. 4). The surface species assigned for magnetite are also valid for maghemite and they appear at almost the same peak frequencies for the two iron oxide surfaces. However, for silicate sorbed from a $5 \mathrm{mM}$ solution, the absorbance ratio $A_{1150} / A_{1020}$ is somewhat larger for the maghemite/silicate system than for silicate on magnetite suggesting that the three-dimensional silica phase is more readily formed on maghemite as compared with magnetite.

The experiments involving maghemite were also encompassing sorption from a $0.4 \mathrm{mM}$ silicate solution (Fig. 5). At this silicate concentration, being in between $1 \mathrm{mM}$ and $0.1 \mathrm{mM}$ (Fig. 4), the band at $950 \mathrm{~cm}^{-1}$ had slightly higher intensity in the beginning of the sorption reaction, relative to the absorption at $\sim 1000 \mathrm{~cm}^{-1}$. The latter band shifts gradually to $1020 \mathrm{~cm}^{-1}$ and increases in intensity as the sorption reaction proceeds. These findings are in accordance with the spectral results discussed above, showing that monomeric silicate species dominates at low silicate concentration whereas oligomeric species become more frequent at higher concentration and at longer reaction times.

\subsection{A comparison between sorption onto magnetite and maghemite}

Another interesting question addressed in this study was the possible difference between magnetite and maghemite concerning their sorption behaviour. The results so far have shown that their qualitative sorption behaviour is rather similar. However, comparing the amount of silicate species sorbed on the two iron oxide surfaces (Figs. 4, 5 and 6), the difference is apparent. The amount
Table 1

Speciation model of dilute silicate aqueous solution based on the reaction: $\mathrm{pH}^{+}+q \mathrm{Si}(\mathrm{OH})_{4} \Leftrightarrow \mathrm{H}_{p}\left(\mathrm{Si}(\mathrm{OH})_{4}\right)_{q^{p+}}$. Formation constants from Felmy [18].

\begin{tabular}{lllc}
\hline$p$ & $q$ & $\mathrm{Chemical} \mathrm{formula}$ & $\log \left(K_{p, q}^{\circ}\right)$ \\
\hline-1 & 1 & $\left.\mathrm{SiO}^{\circ} \mathrm{OH}\right)_{3}{ }^{-}$ & -9.82 \\
-2 & 1 & $\mathrm{SiO}_{2}(\mathrm{OH})_{2}{ }^{2-}$ & -23.27 \\
-1 & 2 & $\mathrm{Si}_{2}[-]$ & -8.50 \\
-2 & 2 & $\mathrm{Si}_{2}[2-]$ & -19.4 \\
-3 & 3 & $\mathrm{Si}_{3}[3-]($ cyclo $)$ & -29.3 \\
-3 & 3 & $\mathrm{Si}_{3}[3-]($ linear $)$ & -29.4 \\
-4 & 4 & $\mathrm{Si}_{4}[4-]($ linear $)$ & -39.1 \\
-4 & 4 & $\mathrm{Si}_{4}[4-]$ (cyclo) & -39.2 \\
-4 & 4 & $\mathrm{Si}_{4}[4-]($ sub $)$ & -39.1 \\
-4 & 4 & $\mathrm{Si}_{4}[2-]$ & -15.6 \\
-6 & 6 & $\mathrm{Si}_{6}[6-]$ & -61.8 \\
\hline
\end{tabular}

of silicate sorbed on magnetite is higher by a factor of 3-5 as compared with maghemite although the structure of the two iron oxides is similar both representing a spinel structure with tetrahedral and octahedral sites. The main physical difference between the two is the unit cell volume being slightly smaller for maghemite caused by the oxidation of the Fe (II) atoms. Both minerals have about the same point of zero charge as determined by Sun et al. and Jarlbring et al. using zeta potential measurements on iron oxide samples prepared by applying a similar synthesis routine as here, viz. at about pH 6.0 for magnetite and at about pH 6.2 for maghemite $[15,19]$. The measured BET areas are also rather similar viz. $98 \mathrm{~m}^{2} / \mathrm{g}$ for magnetite and $87 \mathrm{~m}^{2} / \mathrm{g}$ for maghemite, at least partly due to the similarities between the particle sizes of the two synthesized iron oxides. However, the number of measured proton active adsorption sites is very different for the two iron oxides. As determined by potentiometric titrations, the number of proton active surface sites is about 0.8 sites $/ \mathrm{nm}^{2}$ for maghemite and 5.2 sites $/ \mathrm{nm}^{2}$ for magnetite $[15,19]$. It is therefore proposed here that the number of active surface sites is the main cause of magnetite being a more efficient sorbent for silicate species than maghemite. According to Fig. $6 a$ and $b$, about 3 times more is sorbed at $5 \mathrm{mM}$ silicate concentration and 5 times more at $1 \mathrm{mM}$ silicate concentration after the iron oxide have been exposed to the silicate solutions for about $2 \mathrm{~h}$. It should be noticed that in neither of these two cases, a sorption equilibrium plateau value was reached.

\section{Conclusions}

The sorption of silicate from aqueous solution onto magnetite and maghemite was monitored by in situ ATR-FTIR spectroscopy. From the infrared absorption of silicate species versus time it was concluded that a maximum absorption appeared between $\mathrm{pH} 7.0$ and $\mathrm{pH}$ 9.5. Below pH 9.5, a sorption equilibrium value could not be reached within $2 \mathrm{~h}$. Desorption of already sorbed silicate on a magnetite surface was easier to accomplish at high $\mathrm{pH}(10.8)$ than at low $\mathrm{pH}$ (9.5-7.0). One reason could be the more extensive formation of oligomeric surface silicate species at low $\mathrm{pH}$. At high $\mathrm{pH}$ or low silicate concentration, the dominant surface species were a bidentate monomeric surface complex assigned to the infrared band at $950 \mathrm{~cm}^{-1}$. Decreasing $\mathrm{pH}$ or increasing the concentration of silica implies more of oligomeric surface silicate species assigned to the infrared absorption at $1000-1050 \mathrm{~cm}^{-1}$. At the highest silicate concentration $(5 \mathrm{mM})$ this band shifted from $1020 \mathrm{~cm}^{-1}$ to $1050 \mathrm{~cm}^{-1}$ as the surface loading increased with the time of reaction. Simultaneously, a broad band at $1150 \mathrm{~cm}^{-1}$ grew in intensity, a band that was assigned to a three-dimensional silica framework. The gradual shift from $1000 \mathrm{~cm}^{-1}$ to higher frequency indicated that the degree of polymerization increased with the sorption time and silicate concentration.

The main difference between magnetite and maghemite concerning silicate sorption was the amount sorbed. The amount of 
silicate sorbed onto magnetite was 3-5 times larger than the corresponding sorption onto maghemite.

\section{Acknowledgments}

This research was financially supported by funds donated by LKAB to the Hjalmar Lundbom Research Centre (HLRC) at Luleå University of Technology. Xiaofang Yang thanks the National Natural Science Foundation of China (Grant No. 20537020) for providing the possibility to perform this work in Sweden within a visiting PhD student program.

\section{References}

[1] L. Sigg, W. Stumm, The interaction of anions and weak acids with the hydrous goethite $(\alpha-\mathrm{FeOOH})$ surface, Colloids Surf. 2 (1981) 101-117.

[2] L. Carlson, U. Schwertmann, Natural ferrihydrites in surface deposits from Finland and their association with silica, Geochim. Cosmochim. Acta 45 (1981) 421-429.

[3] C.C. Davis, H.-W. Chen, M. Edwards, Modeling silica sorption to iron hydroxide, Environ. Sci. Technol. 36 (2002) 582-587.

[4] H.L. Shergold, Flotation in mineral processing, in: K.J. Ives (Ed.), The Scientific Basis of Flotation, NATO ASI series, Martinus Nijhoff, Hague, 1984, pp. 229-287.

[5] F.W. Su, K.H. Rao, K.S.E. Forssberg, P.-O. Samskog, Dephosphorization of magnetite fines. 2. Effect of reagents and other chemical variables on apatite flotation kinetics, Trans. Inst. Min. Metall. 107 (1998) C103-C110.

[6] W.Q. Gong, C. Klaober, L.J. Warren, Mechanism of action of sodium silicate in the flotation of apatite from hematite, Int. J. Miner. Process. 39 (1993) 251-273.

[7] P.J. Swedlund, J.G. Webster, Adsorption and polymerization of silicic acid on ferrihydrite and its effect on arsenic adsorption, Water Res. 33 (1999) 3413-3422.

[8] J.W. Phair, J.S.J. van Deventer, J.D. Smith, Interaction of sodium silicate with zirconia and its consequences for polysialation, Colloids Surf. A: Physicochem. Eng. Aspects 182 (2001) 143-159.

[9] J.L. Bass, G.L. Turner, Anion distributions in sodium silicate solutions. Characterization by 29Si NMR and infrared spectroscopies, and vapor phase osmometry, J. Phys. Chem. B 101 (1997) 10638-10644.
[10] H.C.B. Hansen, T.P. Wetche, K. Raulund-Rasmussen, O.K. Borggaard, Stability constants for silicate adsorbed to ferrihydrite, Clay Miner. 29 (1994) 314350.

[11] T. Hiemstra, M.O. Barnett, W.H. van Riemsdijk, Interaction of silicic acid with goethite, J. Colloid Interf. Sci. 310 (2007) 8-17.

[12] N. Jordan, N. Marmier, C. Lomenech, E. Giffaut, J.-J. Ehrhardt, Sorption of silicates on goethite, hematite, and magnetite: experiments and modeling, J. Colloid Interf. Sci. 312 (2007) 224-229.

[13] R.M. Cornell, U. Schwertmann, The Iron Oxides: Structure, Properties, Reactions, Occurrences and Uses, 2nd completely rev. and extended ed., Wiley-VCH Cambridge, 2003.

[14] J.-P. Jolivet, E. Tronc, Interfacial electron transfer in colloidal spinel iron oxide. Conversion of $\mathrm{Fe}_{3} \mathrm{O}_{4}-\gamma-\mathrm{Fe}_{2} \mathrm{O}_{3}$ in aqueous medium, J. Colloid Interf. Sci. 125 (1988) 688-701.

[15] M. Jarlbring, L. Gunneriusson, B. Hussmann, W. Forsling, Surface complex characteristics of synthetic maghemite and hematite in aqueous suspensions, J. Colloid Interf. Sci. 285 (2005) 212-217.

[16] D. Peak, R.G. Ford, D.L. Sparks, An in situ ATR-FTIR investigation of sulphate bonding mechanisms on goethite, J. Colloid Interf. Sci. 218 (1999) 289299.

[17] A. Fredriksson, A. Holmgren, An in situ ATR-FTIR study of the adsorption kinetics of xanthate on germanium, Colloids Surf. A: Physicochem. Eng. Aspects 302 (2007) 96-101.

[18] A.R. Felmy, H. Cho, J.R. Rustad, M.J. Mason, An aqueous thermodynamic model for polymerized silica species to high ionic strength, J. Solution Chem. 30 (2001) 509-525.

[19] Z.X.Sun, F.W.Su, W. Forsling, P.-O. Samskog, Surface characteristics of magnetite in aqueous suspension, J. Colloid Interf. Sci. 197 (1998) 151-159.

[20] G.S. Pokrovski, J. Schott, F. Farges, J.-L. Hazemann, Iron (III)-silica interactions in aqueous solution: insights from X-ray absorption fine structure spectroscopy, Geochim. Cosmochim. Acta 67 (2003) 3559-3573.

[21] V.C. Farmer, Orthosilicate, pyrosilicates and other finite-chain silicates, in: V.C. Farmer (Ed.), Infrared Spectra of Minerals, Mineralogical Society, London, 1974 (Monograph No. 4).

[22] X. Yang, P. Roonasi, A. Holmgren, A study of sodium silicate in aqueous solution and sorbed by synthetic magnetite using in situ ATR-FTIR spectroscopy, J. Colloid Interf. Sci. 328 (2008) 41-47.

[23] K.D. Dobson, P.A. Connor, A.J. McQuillan, Monitoring hydrous metal oxide surface charge and adsorption by STIRS, Langmuir 13 (1997) 2614-2616. 